\title{
Ethnographic reflections on selfhood, embodiment and Alzheimer's disease
}

\author{
PIA C. KONTOS*
}

\begin{abstract}
Explicit in the current construction of Alzheimer's disease is the assumption that memory impairment caused by cognitive deficiencies leads to a steady loss of selfhood. The insistence that selfhood is the exclusive privilege of the sphere of cognition has its origins in the modern western philosophical tradition that separates mind from body, and positions the former as superior to the latter. This dichotomy suggests a fundamental passivity of the body, since it is primarily cognition that is held to be essential to selfhood. In contrast to the assumed erasure of selfhood in Alzheimer's disease, and challenging the philosophical underpinnings of this assumption, this paper presents the findings of an ethnographic study of selfhood in Alzheimer's disease in a Canadian long-term care facility. It argues and demonstrates that selfhood persists even with severe dementia, because it is an embodied dimension of human existence. Using a framework of embodiment that integrates the perspectives of Merleau-Ponty and Bourdieu, it is argued that selfhood is characterised by an observable coherence and capacity for improvisation, and sustained at a pre-reflective level by the primordial and socio-cultural significance of the body. The participants in this study interacted meaningfully with the world through their embodied way of 'being-in-the-world'.
\end{abstract}

$\boldsymbol{K E Y} \boldsymbol{W O R D S}$ - Alzheimer's disease, selfhood, embodiment, being-in-the-world, habitus.

\section{Introduction}

Alzheimer's disease is considered to be the most frightening condition that faces the older population in the 2 ist century (Schroeder et al. I990), and it is a much-feared stigmatising label that carries with it a sentence of social death (Robertson I99I). The source of these fears is the assumption that individuals with Alzheimer's disease or other dementias lose what, according to western culture, defines our humanness: selfhood. As Fontana and Smith (I989: 36) state, with the onset and progression of Alzheimer's disease, what is actually happening is that the self is becoming 'increasingly

* Toronto Rehabilitation Institute, University of Toronto, Canada. 
devoid of content - it is "unbecoming" a self". Davis (2004: 375) echoes these sentiments by maintaining that, "what is so devastating about the relentless nature of dementia is the very splintering of the sedimented layers of Being', until ultimately 'there is nothing left'.

Do we cease to be persons when we lose our memory? Remen (I994: 300-OI), a physician, therapist and professor at the University of California San Francisco School of Medicine, recounts a true story told by a cardiologist, named Tim, to a class of medical students about his father who suffered from Alzheimer's disease. He explains that over a period of Io years, his father had 'slowly deteriorated until he had become a sort of walking vegetable. He was unable to speak and was fed, clothed and cared for as if he were a very young child'. One Sunday, while Tim's mother was out doing the shopping, he and his brother (who were then in their teens), watched football on television as their father sat close by in a chair. As Tim recalls, suddenly his father 'slumped forward and fell to the floor'. His older brother instructed him to telephone 9II, but before he could respond his father spoke for the first time in nearly io years: 'Don't call 9I I, son. Tell your mother that I love her. Tell her that I am all right'. And Tim's father died. Because he died unexpectedly at home, the law required that they have an autopsy: 'My father's brain was almost entirely destroyed by this disease. For many years, I have asked myself, "Who spoke?" I have never found the slightest help from a medical textbook. I am no closer to knowing this now than I was then'.

If the very notion of dementia implies the destruction of selfhood, then indeed 'Who spoke?' This question is difficult to answer because of the disjunction between the described vegetative condition of Tim's father, and the coherence, lucidity and control that he clearly demonstrated shortly before his death. Lucidity and clear communication in the face of advanced Alzheimer's disease are inexplicable, given that cognition and memory have come to be equated with selfhood in western culture (Basting 2003). ${ }^{1}$ This representation of selfhood is itself the legacy of western philosophy's tendency to split mind from body, and to position the former as superior to the latter. This dichotomy suggests a fundamental passivity of the body, since it is primarily cognition that is held to be essential to selfhood. There are thus deep-seated philosophical roots to the prevalent assumption that cognitive impairment implies a loss of selfhood. In this sense, the presumed existential erosion of selfhood with Alzheimer's disease is not simply the result of neuropathology, but is, to a large extent, the consequence of a certain philosophical inheritance. ${ }^{2}$

This paper challenges the mind/body dualism that underlies the assumed loss of selfhood in the current construction of Alzheimer's disease. I advocate a theoretical framework of embodiment (Kontos 2003 $a, 2003 b$, 
2005), which integrates Merleau-Ponty's (I962) radical reconceptualisation of perception and Bourdieu's (1977, I990) theory of the logic of practice. This theoretical framework of embodiment informs the analysis reported in this paper of the findings of an ethnographic study of selfhood in Alzheimer's disease in a long-term care facility in Canada. It is argued that the cognitively impaired residents who participated in this study were actively involved with the world through their embodied way of 'being-inthe-world'. ${ }^{3}$ They interacted meaningfully with the world through activity and engagement rather than contemplation or reflection. My central claim is that selfhood is embodied and characterised by an observable coherence and capacity for improvisation that is sustained at a prereflective level by the primordial as well as the socio-cultural significance of the body.

\section{The ethnographic setting}

Chai Village ${ }^{4}$ is an Orthodox Jewish long-term care facility, located in an urban region of the province of Ontario, and it accommodates 472 residents. The majority suffer from Alzheimer's dementia and a few have vascular dementia. Approximately 80 residents reside on each floor; their average age is 88 years and the great majority $(82 \%)$ are women. The study was conducted during 200I-02 on one of the floors that provide support for residents suffering from Alzheimer's dementia. Of the 79 residents on the floor, I3 participated in the study (three men and Io women). All were Jewish of East European descent, and their cognitive impairment ranged from moderate to severe. ${ }^{5}$

There are richly diverse social activities at Chai Village, with the following among the regular weekly programmes: exercise which involves doing gentle hand, arm and leg movements to music; 'sing-a-long' when residents are encouraged to play musical instruments such as tambourines, and to sing popular Yiddish as well as English songs; and various creative arts including ceramics, silk-scarf painting, drawing, knitting, crochet, weaving and beading. Rosh Hoshanah (the Jewish New Year), Yom Kippur (the day of Atonement), Sukkot (the pilgrimage festival for the completion of the harvest), Simchat Torah (the completion of the cycle of Torah readings), and Hanukkah (the festival of lights) are among the numerous Jewish holidays that are observed. The focal place for the observance of these holidays is the synagogue in Chai Village where a Rabbi leads the services.

Detailed and descriptive field notes were recorded during the observation sessions whenever possible and elaborated afterwards. The field notes included a description of the physical setting(s) where the observations took 
place, the physical things that were present, the actions and interactions of the individuals, the emotions expressed, as well as non-verbal communication (bodily movement and action). Participant observation was conducted over eight months for approximately eight hours per day, three days per week. Observation sessions occurred during scheduled programme activities, Jewish holiday celebrations, meal times, and when participants engaged in unscheduled activities such as walking in the hallways or sitting in the living room. All these activities provided a field of experiential possibilities to observe and explore the ways in which individuals with Alzheimer's disease inhabit their life-world. The following section presents selections of the ethnographic data that exemplify embodied selfhood. The data are organised by the thematic categories of appearance, social etiquette, caring, dancing, and gestural communication, all of which capture the richness and complexity of selfhood as was observed in relationships and communication, expressions of preference and style, social norms and customs, and bodily dispositions, capacities, and practices.

\section{Appearance}

Most of the female residents retained a sense of feminine beauty, and some went to great lengths to attain acceptable self-presentation:

I was walking with Anna ${ }^{6}$ to the social programme and she suddenly stopped and said, 'I need some lipstick'. She leaned over her walker and pulled her purse out of the basket. She dug in her purse and pulled out lipstick and a mirror. She placed the lipstick and mirror on the seat of her walker and turned her walker around so her back was facing the wall. She slowly walked backwards, holding one hand behind her so that she would feel the wall once she reached it, and placed the other hand on the walker. When she reached the wall she let go of the walker and, leaning against the wall with her back, she applied her lipstick while looking into her pocket mirror. Once applied and as she put the lipstick back in her purse she said, 'It makes me look dead without a little colour'. She held the mirror up to her face with her left hand. She licked her right index and middle fingers and, while looking in the mirror, ran her fingers over the left side of her hair in order to pull aside a strand of hair that had fallen out of place. She put the mirror back in her purse and said, 'Let's go honey'.

Sometimes the effort was minimal but nonetheless significant, as when another resident, Sam, paused to wipe with his bib the soup that dripped down his chin, or when Frances placed her hand on her chest, to prevent her blouse from touching the food as she leant over her plate. While attention to appearance was common, Molly's decrepitude, incontinence, helplessness and severe cognitive impairment made the attention she gave to her appearance all the more significant. After the staff secured a bib on 
Molly, a routine procedure, she would reach behind her neck to pull from under the bib a string of pearls so that they could be seen.

\section{Social etiquette}

The manners prescribed by social convention for interaction with others were generally observed by the residents. For example, when Florence complimented Edna on her pink beaded-necklace, Edna replied 'thankyou'. Bertha, the study participant with the most severe cognitive impairment, always said 'thank-you' when her private sitter wiped food from her mouth or chin. Dody routinely said 'good morning' when she sat down at the dining table for breakfast; Florence in turn said 'good morning'; and Molly smiled and acknowledged Dody with a nod. 'Bless you' was always heard from a resident after someone sneezed. Covering one's mouth when yawning, coughing or belching was common. Frances always held her napkin over her mouth when she attempted to remove a stubborn piece of food from her back dentures. Florence never left the dining table without first pushing in the chair. Awareness of and respect for such conventions can be inferred from the strong reactions to those who were not well mannered. The following are two notable examples:

A Health Care Aide buttered some bread, folded it in half and, as she placed it in Molly's hand said, 'Have some bread'. Molly took a bite and as she chewed, she looked up at Dody, who sat directly across from her. Dody was using a napkin to clean her nostrils - twisting the corner of the napkin and inserting it into her nostril, turning it several times and then pulling it out. As Dody inspected the napkin after pulling it from her nose, Molly frowned and abruptly put her bread down on the table. She looked at the Health Care Aide with a scrunched up nose, the corners of her lips curved downwards and furrowed brows. It was an expression of disgust.

Abe belched very loudly in the dining room. Anna, who was seated just one table over, held her hands over her ears and shouted, 'I can't take that. Tell the messhuggener [Yiddish for crazy person] to stop it'.

\section{Caring}

A great deal of affection and physical contact was expressed among the residents, as when a resident very gently touched another's arm, offering comfort to ease agitation. The giving of attention through an open and gentle presence, and looking at and listening to each other, were other ways through which caring was expressed. Whether the residents expressed their sentiments to each other verbally or otherwise, there was no 
uncertainty in these gestures and expressions - they communicated affirmation of one another as human beings. In many instances, the residents responded to a perceived vulnerability or weakness in another, and displayed a sensitivity that suggests a sense of compassion. The following scenes exemplify these exchanges:

After breakfast Dora was in her wheelchair in a line-up of residents against the wall in the hallway. The resident next to her was crying out, 'nurse, nurse', and then started to weep and repeated the same phrase over and over - 'I want to go home'. Dora reached over and placed her hand gently on top of the resident's forearm. Holding her hand there, she sang Tumbalalayka, a Yiddish lullaby.

Abe watched the resident across the table from him as she refused the food that a Health Care Aide was trying to feed her. Abe began to eat his lunch. As he put a spoonful of soup in his mouth he yelled 'ahh-ahm', looking directly at the resident. She looked at Abe and again pushed away the Health Care Aide's hand as she tried to feed her with the soup. Abe yelled 'ah-bababababa-ahm!', as he put another spoonful of soup in his mouth. Anna and Edna were shouting 'shut up!' and meshuggener [crazy person], but he continued nonetheless. Abe looked at the Health Care Aide and asked, "You know why I do that, say "ahm"? Because my neighbour [pointing to the resident across from him] doesn't eat'.

\section{Dancing}

Concerts and sing-a-longs were regular activities in the social programme. They were extremely popular amongst the residents and drew the highest attendances. Most residents knew the words to many of the Yiddish songs. Those who did not know the words sang along with a simple 'la, la, la'. Some residents stood up in excitement as the music played. They danced alone or with a partner, weaving and bobbing across the floor. Others remained seated but clapped, tapped their feet, banged the arms of their wheelchair with their hands or fists, knocked their knees together, swayed their shoulders, or tilted their head from side to side. Dora, though confined to a wheelchair, managed to dance in her own way: she created a sense of fluidity and abandonment, through elegant movements of her arms above her head and delicate finger wiggling while slowly lowering her hands to each side of her wheelchair. Then, dramatically tossing her head back, she extended her arms above her head in an arabesque. Dancing was not confined to the recreation room where the social programmes were held. It was common to see the residents dancing spontaneously and playfully in the hallways, living room or dining room:

A Health Care Aide approached Florence as she walked in the hallway and said enthusiastically, 'Hello gorgeous! You look great!' Florence lifted her arms above her head and shook her hips from side to side and then pushed her hips forward 
and backwards in brisk accentuated movements. Florence laughed with the Health Care Aide. Florence then waved to the Health Care Aide and said, 'Okay, see you on the next one', and continued walking down the hallway.

A Health Care Aide came into the living room and turned on the radio. She listened to the soft music and then walked over to Abe, who was seated on the sofa, holding her hands out for him to take. He grasped her hands and stood up. Standing close together and facing each other, they naturally moved into a dancing position. He put one hand on her waist and she placed one hand on his shoulder, and their free hands clasped together and were held out to the side. Once they were in position, the two began to move, slowly turning in unison, and following the gentle pace of the music. When the song was over, Abe released his hands, slightly stepped back from the Health Care Aide, and bowed. The Health Care Aide smiled and gave him a hug and then helped him back onto the sofa.

\section{Gestural communication}

The residents did not communicate with each other with words alone. Gestures, movements of the body, limbs, hands, head, feet and legs, facial expressions (smiles, frowns), eye behaviour (blinking, winking, direction and length of gaze and pupil dilation) and posture carried implication and meaning. Constantly and everywhere these gestures were employed. They played a large role in inter-personal communication, and often conveyed praise, blame, thanks, support, affection, gratitude, disapproval, dislike, sympathy, greeting or farewell. Slight head nods, eye and small lip movements, chin thrusts, shoulder nods, hand and finger movements, as well as leg and foot shifts were intentional, informative, communicative and interactive. A short sequence of acts might signal for another resident's attention: a directed gaze towards another person, a smile, a lift of an eyebrow, a wave, and a quick head nod. Likewise, gaze avoidance signalled a desire not to communicate, often accompanied by particular body movements or postures, such as turning away:

Edna was seated in the living room, with one leg crossed over the other, swinging her top leg in and out. Dody, seated in an armchair facing Edna, looked directly at her and they became locked in a silent mutual gaze. Dody's eyebrows were knotted and her lips pressed. Edna continued to swing her leg and averted her eyes. Dody suddenly said angrily, 'Why do you move? It's terrible'. Edna's eyes were still averted and, without responding, she continued to move her leg. Dody shifted her body in the chair so that she was sitting on an angle, no longer facing Edna directly. In a further effort to block Edna out of her view, Dody used her left hand to cover her peripheral vision. Still, Dody could see Edna's leg as it swung away from her body towards the centre of the living room. As she muttered under her breath, 'I can't stand this', Dody grasped the left arm of her chair with both 
hands and, using her body weight, made abrupt movements to her right to turn the chair all the way around. This took several laborious minutes. Edna looked at the back of Dody's chair and then abruptly stood up and left the room. Dody watched Edna as she walked down the hallway and, as soon as she had disappeared from view, Dody stood up and pushed her chair around to its original position. Breathing heavily, she sat back in the chair and closed her eyes.

As evinced in the above encounter, gaze is very important, and specifically where residents look, what they look at and for how long. Simply looking at another resident may initiate an encounter. A resident may reciprocate by looking back, and might even expand the encounter with an explosive smile, or decline the invitation by averting the eyes. Another aspect of social interaction was taking turns to speak. Whether their speech was coherent, coherent but unconnected or incoherent, in face-to-face interactions the residents did not vocalise or gesticulate simultaneously but instead observed their turns:

Abe sat down in the dining room and shouted 'bupalupah'. Anna twisted around in her chair so that she could see Abe (his table was behind her's). Abe's face opened up. His eyes grew wider, his mouth eased into a broad smile and he shouted 'brrrrrrr' with first rising and then falling pitch. Anna imitated him, and shouted back 'brrrrrrr' with the same changes in pitch. Abe then shouted 'bah' and paused while looking at Anna. Anna shouted 'shah' and then waited for Abe's response. Abe shouted 'bah', and Anna 'shah', establishing a repeated pattern. Anna eventually turned around in her chair to be seated with her back to Abe. Abe shouted 'bupalupah', as if wanting to initiate another exchange, but Anna instead raised her arm above her head and then swiftly dropped it with a sharp flick of her wrist. With this gesture, she terminated the interaction and they each began to eat their breakfast quietly.

Intonation changes, the rise or fall of pitch level, pauses, and postural shifts were laden with meaning. Anna's postural shift, hand gesture and looking away all definitively terminated the social encounter with Abe.

\section{Embodied selfhood}

The presented ethnographic data clearly demonstrate that the residents of Chai Village were aware of their surroundings, engaged with the world, and interacting with coherence, purpose and meaning. I argue that these aspects of their existence are agential powers fundamental to their being, and define the individual as a person and are thus indicative of selfhood. This is not to suggest that these observable aspects of being exhaust selfhood - even if the residents of Chai Village were not cognitively impaired, all these aspects of their being would be fundamental to their unimpaired selfhood. 
The notion of embodied selfhood that is advocated refers to the complex inter-relationship between primordial and social characteristics of the body, all of which reside below the threshold of cognition, are grounded in the pre-reflective level of experience, and are manifest primarily in corporeal ways. The notion takes its theoretical bearings from MerleauPonty's (I962) under-standing of non-representational intentionality and the primordial body, ${ }^{7}$ and from Bourdieu's (1977, I990) concept of habitus, which links bodily dispositions to structures of the social world. More specifically, it is my claim that selfhood, by residing in the pre-reflective body, has two origins. The first is primordial whereby selfhood emanates from the body's power of natural expression, and manifests in the body's inherent ability to apprehend and convey meaning. Examples of basic bodily movements and sociability, drawn from the ethnographic data, will be analysed with reference to Merleau-Ponty's elucidation of the primordial significance of the body, which is conceptualised as providing the corporeal foundation of selfhood. In this sense, selfhood is tantamount to the existential expressiveness of the body that emerges from our active and responsive propensity towards the world.

The analysis then turns to the second origin of selfhood, the sociocultural dimension of the pre-reflective body. Drawing again from the ethnographic data, the focus is on instances which exemplify the participants' mastery of various social practices as well as the ways in which they mark class distinctions, all of which are socio-cultural manifestations of selfhood. Bourdieu's sociological approach to understanding the embodiment of social structures theoretically informs this analysis of the sociocultural sources of embodied selfhood. The approach entails a shift from the primordial to a social level of existence, because socially and culturally acquired behavioural propensities do not originate in the body. Nonetheless, corporeality remains an active foundation of the meaning that sustains selfhood at a pre-reflective level. ${ }^{8}$

\section{The primordial sources of the coherence of embodied selfhood}

\section{Basic bodily movement}

Central to Merleau-Ponty's (ig62) major work, Phenomenology of Perception, is his argument that embodied consciousness (to which he refers interchangeably as 'embodied significance', 'non-representational intentionality' and 'basic intentionality') is a fundamental level of existence that does not involve cognitive consciousness. Merleau-Ponty's basic intentionality is the body's concrete, spatial and pre-reflective directedness towards the lived world. The pre-reflective moving body is in and of itself intentional 
by virtue of being invested with perceptual significance, a bodily know-how or practical sense. He argues that the body in movement is not limited to passive submission to space and time, for it actively and intentionally takes up elemental significance. In Merleau-Ponty's words (1964:5), 'a system of possible movements ... radiates from us to our environment', giving us at every moment a practical and implicit hold on our body, a hold that situates us as subjects perceptually and linguistically, as well as through motor activity. I understand selfhood as inherent in what Merleau-Ponty describes as corporeal and non-reflective intentionality, and therefore argue that selfhood must be understood as being enacted in the body's movements. In a 'system of possible movements', the body possesses, according to Merleau-Ponty, a co-ordinating power in relation to itself, through what he refers to as the 'primary perceptual' level that is prior to explicit intellection. He cites an example of the pre-reflective nature of the co-ordination of visual, tactile and motor aspects of our body:

When bitten by a mosquito, we do not need to look for the part of the body where we have been bitten. We find it straight away by reaching with our hand the itchy spot on our phenomenal body. We do not locate it in relation to axes of co-ordinates in objective space. In the natural system of our own body, we experience a direct relationship between our hand as a scratching potentiality and the part of our body bitten as a spot to be scratched' (Merleau-Ponty ig62: I05-6).

Similarly in Chai Village, when Molly reached behind her neck to pull her pearls from beneath her bib, she 'knew' where her hand was, and how far and at what angle she had to reach to grasp the pearls. When Anna applied lipstick while leaning for support against the hallway wall, she not only knew where her hand was but also mobilised all the postural adjustments required to execute the action while maintaining her balance. Molly and Anna intended a certain outcome by their actions, and the enabling actions were spontaneously distributed amongst the appropriate parts of their bodies. In fact, in all the examples where physical movement was involved, the movements of the residents were perfectly suited to the circumstances and they did not have to reflect on the principles upon which their actions were based. For example, with the movements involved in gestural communication and dancing, the residents did not launch their bodies into blind attempts to perform an action, rather every movement had inextricable intentionality. Because intentionality is fundamental to our existential being, it is more accurate to say that movement is inextricably embodied selfhood. Thus, in the case of my study participants, selfhood can be observed in movement where movement attests to their hold on the general synthesis of their bodies, a hold that Merleau-Ponty argues emanates from our primordial bodily schema. 
In addition to having a hold on the general synthesis of their body, the residents had a pre-reflective sense of and grasp of their environment, as evinced by their capacity to move around in and to utilise space without first having to think how to do so. Merleau-Ponty (1962: I43), in an analysis of motility, gives the example of a woman who, without any calculation, keeps a safe distance between the feather in her hat and elements of the external environment that might damage it. When she passes through a doorway, for example, she 'feels' where the feather is, just as she 'feels' where other parts of her body are, and thus it is unnecessary for her to measure the distance between the tip of her feather and the top of the doorway to judge whether she can safely pass. Merleau-Ponty uses this example to illustrate the body's power to appropriate 'fresh instruments' into its schema.

I suggest that for those residents who used a walker as an aide, it was like the feather in the woman's hat, in the sense that the walker had ceased to be an object with a size and volume that was established by comparison with other objects. When the residents used their walker, there was no question of comparing the dimensions of the walker and the space through which they wished to pass - just as we all go through a doorway without checking the width of the doorway against that of our body. This must necessarily be so because the residents could not conceivably navigate themselves if, on every occasion they had to evaluate the respective measurements of their walker and the space to be navigated. There was a recognisable fluidity to their gait: it had not become, as a result of the walker, a sequence of partial movements strung laboriously together. The walker had ceased to be an object, for its legs had become an area of sensitivity, akin to another of Merleau-Ponty's (I962: I52) examples, the blind man's stick, which he argues becomes an instrument with which the blind man perceives.

Just as the stick extends the scope and active radius of the blind man's touch and movement, the walker had become an extension of the bodily schema of the residents, in that the position of things is immediately given to them through the reach of their extended arms and the range of the walker's movement. Although the participants acquired the walkers in old age, they had all managed to adapt to its use with tremendous facility, as if they had had them since childhood. This is because, according to MerleauPonty (1962: I43), the blind man's walking stick, or other walking aid, is incorporated within our bodily schema: the object becomes an extension of one's body. It can be seen in these examples of basic bodily movement that selfhood persists in the body's affinity with its surroundings, its potential aptly to seize those surroundings, and its adaptability to incorporate new objects into the bodily schema. 
It is suggested that we think of Merleau-Ponty's notion of the perspectival unity of corporeal schema as providing a foundational structure for selfhood, a structure that itself comprises perception as embodied consciousness. Thus, fundamental to the coherence of selfhood is the unique synthesis of movement and embodied perception through the body's ability to seize upon and transform the perceptible into something meaningful. The way that my study participants unthinkingly carried and projected their bodies disclosed a coherence and unity in their directedness towards the world. It is this unity that, at a fundamental level, allowed the participants to grasp external space and engage mutually with others. In summary, it is argued that the bodily schema, the primordial unity of the body, is the foundation of a coherent embodied selfhood.

\section{Sociability}

The coherence of embodied selfhood is also manifested in the successful accomplishment of social interaction. The residents of Chai Village were not operating in their own private worlds, but on the contrary were participants in a common world, communicating with one another. To understand the words of another person, a vocabulary and syntax must already be known. Merleau-Ponty (I962: I83) argues, however, that words do not do their work by arousing representations associated with them. Language has inner content but the meaning of words is not entirely contained in the words themselves: rather, their meaning emerges from and is influenced by the contextual discourse. During interactions, words assume a gestural significance to the extent that their conceptual meaning is formed by inference from the gestural meaning. Thus, even with language, Merleau-Ponty detects certain corporeal tendencies, or more specifically, that the perspectival unity of corporeal schema underscores the primacy of embodiment in speech itself. I argue further that, because selfhood resides in corporeality, language and especially the gestures that accompany speech provide further opportunities for the exploration of bodily manifestations of selfhood.

Merleau-Ponty's argument that speech is a gestural system is perhaps most apparent where no linguistic meaning at all is conveyed by speech. This is so because in such instances individuals are still able to communicate with each other through the expressive dimensions of the gesticulating body, which are fundamental to communication in human interaction. Even when the speech was incoherent and void of linguistic meaning, as during Abe's and Anna's verbal exchange in the dining room, they vocalised alternately as well as gesticulated back and forth. With only utterances of 'bah', 'shah, 'brrrrr' and 'bupalupah', Abe and Anna were 
able to communicate without recourse to intellectual interpretation. Selfhood manifested in the fit, i.e. the contained meanings of the rise and fall of the pitch of their voices, the pauses and the postural shifts. Selfhood was also disclosed in their gestures, which had a rhythmic flow and fluent form. Abe's and Anna's verbal exchange exemplifies very well Merleau-Ponty's (I964: 7) assertion that communication dwells in corporeality or, more specifically, in the body's capability of gesture. Because of Abe's speech impairment and Anna's jesting mimicking, the force of their utterances derived not from the semantic content but rather from the meanings that their bodies directly indexed. Communication was thus a continuation of the corporeal schema. I therefore claim that selfhood persisted in and through their bodies' powers of natural expression, that is, the body's inherent ability to apprehend and convey meaning.

\section{Socio-cultural sources of the coherence of embodied selfhood}

\section{Mastery of the social world}

We saw with Merleau-Ponty that the body has a primordial capacity for movement and gesture, a capacity that he describes as a power of signifying or expressing (1962: 169,376$)$. It is crucial to bear in mind that in Merleau-Ponty's discussion of the primordial capacity of the body, he makes no reference to socio-cultural modes of expression because his exclusive concern is with capacity per se. Clearly, however, there is a sociocultural style or content to bodily movements and gestures, the source of which is not attributable to a primary level of signification. Bourdieu's concept of habitus is pertinent here because it foregrounds the sociocultural sources of bodily practices.

Habitus comprises dispositions and forms of know-how, which function below the threshold of cognition and are enacted at a pre-reflective level. As Bourdieu (1984: 466) states, 'the schemes of the habitus, the primary forms of classification, owe their specific efficacy to the fact that they function below the level of consciousness and language, beyond the reach of introspective scrutiny or control by the will'. Wacquant (I992: 20), perhaps Bourdieu's best commentator, notes that Bourdieu is clearly drawing on Merleau-Ponty's idea of the body as the source of practical intentionality and of inter-subjective meaning grounded in a pre-objective level of experience. The body is treated as a 'generative, creative capacity to understand' - as a kind of corporeal awareness - as a practical reason, with reason existing primarily in corporeal ways. With the concept of habitus, Bourdieu investigates practice in the context of the social genesis of its conditions of operation. Thus, Bourdieu's exploration of competence, 
know-how, skill and disposition leads him into the socio-cultural domain in which bodies assume their significance.

It is my argument that in addition to having a primordial source, selfhood resides in the dispositions and generative schemes of habitus and thus, as dispositions are embodied and materialised in practice, so selfhood is embodied and manifests itself in socio-culturally specific ways of beingin-the-world. Thus embodied selfhood owes its coherence not only to the foundational unity of the body, but also to the embodiment of culturespecific conditions of primary socialisation. This is apparent when we consider the coherence and consistency in the residents' mastery of their social world, and in the ways that the residents embraced their daily routines and engaged in specific activities. There was, for example, an observably coherent and consistent intelligibility to the participants' management of the social demands of eating in the dining room. They were immediately familiar with the proper use of utensils, napkins and condiments. Furthermore, when the residents sat at the table and ate their meals, they socialised with one another and for the most part respected table etiquette. The steadiness and persistence of the rhythm of the daily interactions owed their regularity and predictability to the social history and culture that produced the dispositions of the residents, and which, following the logic of habitus, continued to harmonise their behaviour without any deliberation or conscious reference to a norm, and without conscious co-ordination (Bourdieu I990: 58-6o). To elaborate Bourdieu's argument, I suggest that the determinations attached to one's primary socialisation and cultural environment give selfhood its socio-cultural specificity by virtue of being embodied and materialised in our habitual state, tendencies and inclinations to act in a particular way. In this respect, the quotidian interactions at Chai Village were regulated not through the residents' conscious obeisance to external rules but because the taken-forgranted, pre-reflective nature of their practices flowed from embodied selfhood.

Mastery of a common code is evident not only where there is a regularity of social practice, but also when something happens that deviates or contradicts the customary code, as when a resident who failed to adhere to the proper etiquette met with the disapproval of the other residents. For example, when Abe belched loudly in the dining room and Anna held her hands over her ears and yelled 'tell the messhuggener to stop it', it is clear that Abe's behaviour had offended. Anna's reaction can be interpreted as a negative sanction because Abe's behaviour departed too far from what she had internalised as appropriate behaviour. As Bourdieu argued (I990: 6I), 'habitus tends to favour experiences likely to reinforce it ... to protect itself from crises and critical challenges by providing itself with a milieu to 
which it is as pre-adapted as possible'. A similar disjunction between habitus and objective conditions occurred when Molly furrowed her brows and abruptly stopped eating when she saw Dody using the twisted corner of a napkin to clean her nostrils. The behaviour of Abe and Dody was deemed improper and intolerable, which attested to the persistence of embodied selfhood. Put simply, behaviour is negatively sanctioned when it offends the sensibility of one's selfhood.

\section{Selfhood as an expression of class distinction}

Bourdieu recognises important connections between the social determinations that attach to specific positions in social space and the body's dispositions. Since habitus produces practices that accord with the regularities of the conditions of existence, taste and etiquette, Bourdieu (ig84: 466) interprets these practices as markers of underlying class distinctions which provide a 'sense of one's place'. Because I maintain that selfhood consists in the dispositions and generative schemes of habitus, Bourdieu's argument can be elaborated to suggest that selfhood too has the mark of class distinction.

Class distinctions at the corporeal level amongst the residents of Chai Village become evident if we consider how the propensities and movements of the body are socially qualified. For example, Edna was aggressive and boastful, in marked contrast to Dody's propriety and modesty: she objected to Edna's indecorous and brazen manner. There was another contrast between the excessive swing of the hips in Edna's heavy stride and Molly's small and delicate walking steps. Molly's delicate manners were also apparent when she used a Kleenex tissue to softly wipe the tip of her nose while Edna, in contrast, covered her entire nose, clenched it tightly with the tissue and blew loudly. In these examples we see physical expressions of class distinctions and, to this extent, equivalences between the differentiations of the social world and selfhood.

All these propensities and movements of the body are socially qualified. This is so because, according to Bourdieu, each habitus embodies both the material conditions of existence of a class and the symbolic differentiations that categorise and rank its relation to other classes. Individuals are then predisposed to make lifestyle choices characteristic of their class habitus (Bourdieu I984: I72). The class distinctions amongst the residents of Chai Village should not obscure the fact that each resident's manifestations of selfhood had internal consistency and coherence: all manifestations were congruous with and representative of the individual's social class. This was apparent in, for example, the concordance between Molly's silk blouses ${ }^{9}$ and pure white pearls, the way in which she crossed her legs and clasped 
her hands in her lap when seated, and the polite manner in which she wiped the tip of her nose. There was similar congruence in Edna's actions: the excessive swinging of her hips while walking, her aggressive salting of her meal, her loud nose blowing, and her style-less dress of loose-fitting sweaters and dated costume jewellery.

\section{Innovation and spontaneity}

Coherence in the distinctiveness of embodied selfhood is also evident if we consider the participants' sociability and the ways in which they combined social interaction with innovation. The residents had a grasp of the multiple meanings and innuendoes expressed in gestures in interactive situations. This was most apparent where the same gesture was made in very different contexts. One of the most commonly used Yiddish gestures ${ }^{\mathbf{1 0}}$ is to fling one or both hands in front of the body swiftly downwards, with the elbows held close to the body and a simultaneous turn of the head slightly away from the person with whom one is engaged. In one context this gesture expresses disapproval, as when Anna was angered by Abe's loudness in the dining room. The same gesture, in another context, expresses 'don't worry about it', as when Anna used it while saying 'it's nothing' to persuade Goodie to forget whatever was bothering her. In both contexts, however, the gesture carried a dismissive sense, in the former one of criticism, and in the latter of consolation and encouragement.

Distinctiveness was also evident in the residents' ability to be inspired by the moment and to be spontaneous. Dora, for example, sang on her own accord, while Edna when strolling down the hallway often stopped to look at the paintings on the wall; and Anna glanced at her wedding band and engagement ring while quietly sitting alone. Even when prompted by others, there was spontaneity in their openness to situations. For example, when Abe was prompted by a member of the staff to take her hand, he slowly danced to the song being played on the radio; and when a ball was playfully tossed to Anna, she threw it back. Spontaneity and improvisation were also exemplified in the dining room: at no two meals were the interactions identical, which counters any notion of advanced orchestration or rote repetition. In all these instances, the body expressed meanings which can be read as providing a framework for numerous experiences. In this regard, selfhood does not reside in organic processes but in human gestures and movements that issue from these processes. In other words, these examples are incomprehensible if selfhood is understood as mechanistic or even as a cluster of instincts. 
These examples of spontaneity resonate with Bourdieu's argument that habitus should not be understood as mechanically constraining action but rather as permitting an element of inventiveness and creativity, albeit within the limits of its structures, which are the embodied sedimentations of the social structures which produced it. Wacquant (1992: 22) aptly describes this element of inventiveness when he refers to habitus 'as a generative spontaneity which asserts itself in the improvised confrontation with endlessly renewed situations' and argued that it 'follows a practical logic, that of the fuzzy, of the more-or-less, which defines the ordinary relating to the world' (original emphasis). It is this fuzzy and vague but no less acquired mastery that makes it possible to respond instantaneously, coherently, and creatively to the many uncertain and ambiguous situations of practice. Following the logic of habitus, spontaneity and improvisation are the product of the embodiment of culture-specific conditions of primary socialisation, which I argue is a source of the creative capacity of embodied selfhood.

The engagement of selfhood with the world consisted primarily in the residents' intrinsic corporeality of being-in-the-world. I have argued that this implies that selfhood is a synthesis of primordial and social being. In this synthesis the Chai Village residents' socio-cultural manner of being did not suppress their primordial existence but constantly utilised the primordial hold of their body in relation to the world. In other words, the expressiveness of the residents disclosed a cultural particularity that was shaped by socialisation, but the expressiveness was dependent upon the perspectival unity of the body for the actual expression of selfhood through bodily movement and gestures.

\section{Conclusion}

The disparate and discursive literature on Alzheimer's disease and other dementias reads as a catalogue of horrors and documents of fear, dread and loss. It is through modern science and its deep philosophical roots that Alzheimer's disease and its symptoms are thought to signal the erasure of selfhood. This paper has articulated an alternative vision, one that captures the ways in which selfhood is embodied and reproduced non-discursively through our practical and corporeal actions. Following Merleau-Ponty and Bourdieu, it has been argued that the existential and social aspects of the body are indispensable for the articulation of selfhood. The coherence of selfhood and its generative spontaneity persist despite the presence and progression of Alzheimer's because it resides below the threshold of cognition and in the pre-reflective level of experience. 
If we could shift the discourse on selfhood in Alzheimer's disease towards a greater recognition of the way that humans are embodied, it would critically challenge the widespread presumption of the loss of agency with cognitive impairment. It would do so by disentangling selfhood from the cognitive categories upon which long-standing notions of selfhood are presumed, and it would ground selfhood in corporeality. The concept of embodied selfhood by no means encapsulates all aspects of body-self and body-world relations, nor is it intended to resolve the debate about the self in Alzheimer's disease. Rather it promotes a perspective on the body and selfhood that provides new insight and direction for future investigation of Alzheimer's disease, and more broadly of embodied ways of being-inthe-world.

\section{Acknowledgments}

This article is based on my doctoral research undertaken in the Department of Public Health Sciences, University of Toronto. I gratefully acknowledge the financial support of the Alzheimer Society of Canada and the Institute of Aging (Canadian Institutes of Health Research) (Award 03-07). I also wish to express my thanks to Ann Robertson, Stephen Katz and Gail Mitchell whose constructive and insightful comments were invaluable to the development of my research.

\section{NOTES}

I Increasing numbers of social scientists and health science scholars are challenging the dominant paradigm of dementia which ties selfhood exclusively to cognition (Bond I992; Downs 1997; Golander and Raz I996; Gubrium I986; Kitwood I990, I993, I997; Lyman 1989, I998; Post 1995, I998; Sabat and Harré 1992; Vittoria 1998). Scholars who have endeavoured to reframe and reclaim the self in Alzheimer's disease have been much influenced by a social interactionist perspective, which emphasises the aspects of treatment contexts and care-giving relationships which damage dementia sufferers' fragile self-esteem, and ultimately brings about the loss of selfhood that is so widely thought to be caused by neuropathology (Bond I992; Kitwood I993, 1997; Lyman 1989, I998; Post 1995; Sabat and Harré 1992). One of the key ideas of interactionist social theory is that the origin of the self is social in that it is guaranteed through social interaction. Conceptualising personhood in this way challenges the notion that the personal deterioration associated with dementia comes about simply as the result of a neurological process that has its own autonomous dynamic. While to embrace a view of personhood that hinges on social interaction provides a crucial critique of the dominant paradigm of dementia in which personhood is completely denied, it is a perspective that relegates the body to a symbolic role where it is understood as being representative of meaning rather than as a significant dimension of selfhood. Conceptualising selfhood as essentially 'the human being in relation to others' (Kitwood and Bredin 1992: 275) is to miss something vital about personhood, namely, how capacities and the senses of the body are central to the very notion of selfhood, and are not derived from social interaction but rather from the inherent nature of our embodied existence (Kontos 2003a). 
2 My perspective should by no means minimise the importance of the humanistic pursuits of professionals and care-givers committed to patients and residents with the disease, nor should it diminish the challenges faced by those who live with this illness.

3 The concept of 'being-in-the-world' was introduced to 2oth-century philosophy by Heidegger (see Matthews 2002 for a comprehensive discussion of the philosophical origins of the concept). However, my use of the concept is in the context of MerleauPonty's philosophy.

4 To ensure that the identity of this home for the aged is protected, a pseudonym is used.

5 Cognitive impairment was measured with the Mini Mental State Examination (MMSE), a widely used method for assessing cognitive mental status (Folstein, Folstein and McHugh 1975). Among the study participants, the mean MMSE score was II.3, the range was I-I5 (mild I9-24, moderate IO-I8, severe $\mathrm{o}^{-\mathrm{IO}}$ ) (Jones et al. 2004), and 39 percent were severely cognitively impaired. Because of cognitive impairment, informed consent to participate was provided by proxy.

6 All names of the residents are pseudonyms.

7 Terms such as 'non-representational intentionality' and 'primordial' have been taken up by different scholars in critical thought and, as a consequence, have acquired diverse and often disparate meanings. When I elaborate Merleau-Ponty's philosophical approach to the body, my use of these terms is confined to his intended meaning. When however I apply these ideas to my analysis of embodied selfhood, something that Merleau-Ponty did not address, I am clearly extending the meaning and usage of these terms.

8 It is important to bear in mind that though my theoretical articulation of embodied selfhood takes its bearings from Merleau-Ponty's and Bourdieu's theoretical perspectives on the body, it emerges fully by extending their thought through analysis of the ethnographic data.

9 Although the residents' clothing was purchased by their relatives, new garments were always in keeping with the style of the residents' wardrobe. In other words, the new garments brought by spouses, children or grandchildren were always a close variation of the items to be replaced. Hence, even in an institutional setting, dress continues to reflect class distinctions amongst the residents, distinctions that were established prior to their taking up residence in Chai Village.

Io Facial expressions and body movements were distinctive and predominant manifestations of selfhood in communication amongst my participants. When the residents interacted with one another, so identifiably Jewish were their non-verbal forms of communication that a person of Jewish heritage would not need to know that Chai Village is a Jewish facility to recognise instantly that the residents are Jewish. Following Bourdieu, we could say that their Jewishness is embodied in their arms, hands, feet and head, which underscores the essence of habitus, the embodiment of culturespecific conditions of primary socialisation. My analysis in no way attempts to essentialise a primordial Jewish set of bodily characteristics. On the contrary, my analysis demonstrates how the culture-specific conditions of socialisation became for the participants an important resource for bodily expressions of their selfhood.

\section{References}

Basting, A. 2003. Looking back from loss: views of the self in Alzheimer's disease. Fournal of Aging Studies, I 7, 87-99.

Bond, J. 1992. The medicalization of dementia. Fournal of Aging Studies, 6, 397-403. 


\section{Pia C. Kontos}

Bourdieu, P. I977. Outline of a Theory of Practice. Cambridge University Press, Cambridge.

Bourdieu, P. 1984. Distinction: A Social Critique of the Fudgement of Taste. Harvard University Press, Cambridge, Massachusetts.

Bourdieu, P. 1990. The Logic of Practice. Polity, Cambridge.

Davis, D. 2004. Dementia: sociological and philosophical constructions. Social Science and Medicine, 58, 369-78.

Downs, M. I997. The emergence of the person in dementia research. Ageing \& Society, I 7, $597-607$.

Folstein, M., Folstein, S. and McHugh, P. 1975. Mini-mental state: a practical method for grading the cognitive state of patients for the clinician. Fournal of Psychiatric Research, I 2 , I96-8.

Fontana, A. and Smith, R. W. I989. Alzheimer's disease victims: the 'unbecoming' of self and the normalization of competence. Sociological Perspectives, 32, I, 35-46.

Golander, H. and Raz, A. E. I996. The mask of dementia: images of 'demented residents' in a nursing ward. Ageing \& Society, I6, 269-85.

Gubrium, J. F. 1986. Oldtimers and Alzheimer's: The Descriptive Organization of Senility. JAI, Greenwich, Connecticut.

Jones, R., Soininen, J., Hager, K., Aarsland, D., Passmore, P., Murthy, A., Zhang, R. and Bahra, R. 2004. A multinational, randomised, I2-week study comparing the effects of donepezil and galantamine in patients with mild to moderate Alzheimer's disease. International Fournal of Geriatric Psychiatry, 1 9, 58-67.

Kitwood, T. I990. The dialectics of dementia: with particular reference to Alzheimer's disease. Ageing \& Society, ro, I77-96.

Kitwood, T. I993. Towards a theory of dementia care: the interpersonal process. Ageing \& Society, 13, 5 $5^{\mathrm{I}-67}$.

Kitwood, T. 1997. Dementia Reconsidered: The Person Comes First. Open University Press, Buckingham.

Kitwood, T. and Bredin, K. I992. Towards a theory of dementia care: personhood and well-being. Ageing \& Society, I 2, 269-87.

Kontos, P. 2003a. Embodied Selfhood: An Ethnography of Alzheimer's Disease. Unpublished Ph.D Dissertation, University of Toronto, Canada.

Kontos, P. 2003 $b$. 'The painterly hand': embodied consciousness and Alzheimer's disease. Fournal of Aging Studies, I 7, I5 I-70.

Kontos, P. 2005. Embodied selfhood: redefining agency in Alzheimer's disease. In Tulle, E. (ed.), Old Age and Agency. Nova Science, Huntington, New York, forthcoming.

Lyman, K. I989. Bringing the social back in: a critique of the biomedicalization of dementia. The Gerontologist, 29, 5, 597-605.

Lyman, K. A. 1998. Living with Alzheimer's disease: the creation of meaning among persons with dementia. Fournal of Clinical Ethics, 9, I, 49-57.

Matthews, E. 2002. The Philosophy of Merleau-Ponty. McGill-Queen's University Press, Montreal and Kingston, Ontario.

Merleau-Ponty, M. i962. Phenomenology of Perception. Routledge and Kegan Paul, London.

Merleau-Ponty, M. ig64. An unpublished text by Maurice Merleau-Ponty: a prospectus of his work. In Edie, J. (ed.), The Primacy of Perception. Northwestern University Press, Evanston, Illinois, $3-$ I I.

Post, S. I995. The Moral Challenge of Alzheimer Disease. Johns Hopkins University Press, Baltimore, Maryland.

Post, S. 1998. The fear of forgetfulness: a grassroots approach to an ethics of Alzheimer's disease. The Fournal of Clinical Ethics, 9, 7 $\mathrm{I}-80$.

Remen, R. N. 1994. Kitchen Table Wisdom. Riverhead, New York. 
Robertson, A. I991. The politics of Alzheimer's disease: a case study in apocalyptic demography. In Minkler, M. and Estes, C. L. (eds), Critical Perspectives on Aging: The Political and Moral Economy of Growing Old. Baywood, Amityville, New York, 135-50.

Sabat, S. and Harré, R. I992. The construction and deconstruction of self in Alzheimer's disease. Ageing \& Society, I 2, 443-6I.

Schroeder, S., Krupp, M., Tierney, L. and McPhee, S. 1990. Current Medical Diagnosis and Treatment. Appleton and Lange, Norwalk, Connecticut.

Vittoria, A. K. 1998. Preserving selves: identity work and dementia. Research on Aging, 2o, I, 9I-I36.

Wacquant, L. I992. Toward a social praxeology: the structure and logic of Bourdieu's sociology. In Bourdieu, P. and Wacquant, L. (eds), An Invitation to Reflexive Sociology. University of Chicago Press, Chicago, 2-59.

Address for correspondence:

Accepted 23 March 2004

Pia Kontos, Toronto Rehabilitation Institute, University Centre, 550 University Avenue, Suite I124, Toronto, Ontario $\mathrm{M}_{5} \mathrm{G}_{2} \mathrm{~A}_{2}$, Canada.

e-mail: kontos.pia@torontorehab.on.ca 